G. C. Young

D. W. Holladay

Chemical Technology Division

Oak Ridge National Laboratory*

Oak Ridge, Tennessee 37830

\author{
Paper for presentation at the 74th Annual Meeting \\ of the American Institute of Chemical Engineers \\ November 8-12, 1981 \\ New Orleans, Loulsiana
}
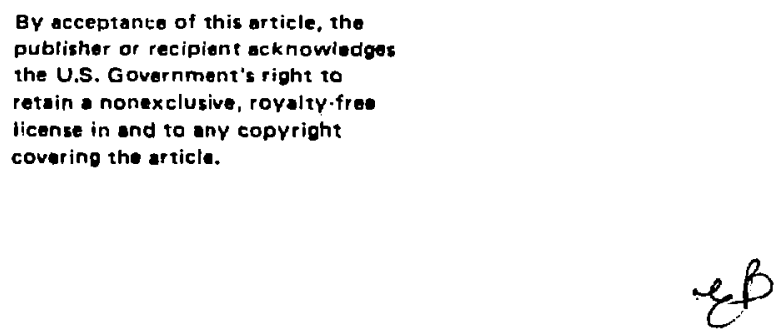

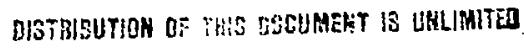

*Operated by Union Carbide Corporation for the U. S. Department of Energy. 


\title{
RECOVERY OF ACID-DEGRADED TRIBUTYL PHOSPHATE BY SOLVENT EXTRACTION*
}

\author{
G. C. Young \\ D. W. Holladay
}

Chemical Technology Division Oak Ridge National Laboratory .Oak Ridge, Tennessee 37830

\begin{abstract}
During nuclear fuel reprocessing the organic solvent becomes loaded with various acjdic degradation nroducts, which can be effectively removed through solvent extraction. Studies have been made with a small bench-scale solvent extraction system to optimize such parameters as $\mathrm{pH}$ of aqueous phase, phase ratio, residence time, flow rates, and temperature. The necessary decontamination factors have been obtained for various degradation products during continuous solvent extraction in one stage, with the aqueous phase being recycled. The aqueous phase contains compounds that can be degraded to gases to minimize waste disposal problems.
\end{abstract}

*Research sponsored by the Office of Nuclear Fuel Cycle, U.S. Department of Energy under contract W-7405-eng-26 with Union Carbid: Corporation. 


\section{INTRODUCTION}

The purpose of this paper is to describe the construction and operation of a small, bench-scale apparatus for the study and evaluation of new solvent extraction processes. The utility of the apparatus is illustrated by some results obtained by scrubbing impurities from 30 vol \% tributyl phosphate (TBP) in normal paraffin hydrocarbon diluent (primarily dodecane) with an aqueous hydrazine oxalate solution.

During reprocessing, about $10^{-4}$ mole fraction of the $\mathrm{TBP}(30 \% \mathrm{TBP}=1.1 \underline{\mathrm{M}}$ TBP) undergoes radiolysis and chemical hydrolysis to produce dibutyl phosphoric acid (DBP) and monobutyl phosphoric actd (MBP) in a DBP/MBP molar ratio of approximately 10 . The concentrations of these impurities must be reduced by a factor of 10 or greater in order to recycle the solvent; otherwise, low recoveries and purlties of the fuel values will result. This adverse effect occurs because alkylphosphoric acids are powerful cation exchangers which bind quadrivalent and hexavalent elements tightly to the solvent phase under acidic conditions. In addition, excessive concentrations of DBP and MBP produce interfacial precipitates or emulsions (due to the sparingly soluble alkylphosphate compounds formed with zirconium and uranium), which hamper phase separations and equipment operation. Finally, it is necessary to recycle the solvent because of its cost and to avoid storage of unwieldy volumes of a radioactive organic waste liquid.

In the past the spent solvent has been purifled by scrubbing it with an aqueous solution of sodium carbonate. The spent scrubber solutions are the 
source of a significant quantity of contaminated sodium salt waste. Scrubber solution consumption is primarily due to the residual nitric acid content of the solvent after back-extraction of fuel values with dilute nitric acid. Since hydrazine can be decomposed electrolytically by anodic reaction or by chemical reaction with nitrous acid into volatile nitrogen and water, scrubbing with hydrazine salts has been proposed as a method for reducing the quantities of salt wastes. The chemical feasibility of, removing impurities by scrubbing with .aqueous hydrazine salt solutions had previously been demonstrated in batch equilibrium studies in the laboratory. The scrubbing coefficient, $D_{s}$, for the various impurities in the spent solvent, as defined in Eq. 1, was found to be in the range 500 to 1000 for all impurities:

$$
D_{s}=\frac{C_{a 1}}{C_{o 1}}
$$

where $\mathrm{C}_{\mathrm{aI}}$ and $\mathrm{C}_{\mathrm{oi}}=$ concentrations of the impurity in the scrubber phase
and the solvent phase, respectively. Values of $D_{s}$ in this range permit the treatment of 50 to 100 volumes of solvent with one volume of scrubbing solution while achieving the desired goal of a tenfold reduction in impurity concentrations. An aqueous hydrazine oxalate solution was used as the scrubbing agent in the present study because previous laboratory studies had indicated that complex formation between oxalate ion and metal cation impurities in the aqueous phase would enhance the removal of alkylphosphoric acid-bound metal cations from the organte phase and perhaps also permit higher scrubber solution loadings of the sparingly soluble alkylphosphoric salts formed with quadrivalent and hexavalent elements. 
A continuous, bench-scale, mixer-settler apparatus was used in the present study to Indicate the engineering feastbility and to obtain additional chemical data for the hydrazine oxalate scrubbing process. This apparatus is of general utility for the preliminary evaluation of solvent extraction processes with regard to the effects of the important physical and chemical process parameters.

\section{EQUIPMENT REQUIREMENTS}

To determine the feasibility of the $\left(\mathrm{N}_{2} \mathrm{H}_{5}\right)_{2} \mathrm{C}_{2} \mathrm{O}_{4}$ scrubbing method, it is necessary that the apparatus provide a convenient means of determining the effects of the temperature and the chemical parameters on overall process performance with respect to (1) the ease of phase separations, (2) the formation of interfacial precipitates or emulsions on buildup of impurities in the aqueous phase, and (3) the degree of purification of the 30\% TBP that is achieved. The important chemical parameters are the acidity (or $\mathrm{pH}$ ) and the degree of loading of the scrubbing solution with. the various impurities.

Mixer-settlers are the most convenient equipment for evaluating solvent extraction processes because a given equilibrium stage is well isolated froril adjacent equilibrium stages. This ensures that good stage data are obtained. Appropriate in-line sampling or instrument probe ports must be provided so that the necessary chemical data are obtained. It is also advantageous to have the mixing and settling compartments constructed of glass so that direct visual observation can be made. Means for recycle of the transfer phase are highly desirable because this is the most convenient way to study solute loading effects on the transfer phase. 
The Impurity level in the treated solvent phase (30\% TBP) will increase with the number of recycles of the scrubber solution according to the following Kremser-type equation:

$$
\frac{1}{\mathrm{DF}}=1-\left(\frac{E_{s}}{1+E_{s}}\right)^{n},
$$

where $D F=\frac{C_{u s}}{C_{t s}}$, the decontamination factor;

$C_{t s}$ and $C_{u s}=$ concentrations of Impurity, 1 , in treated solvent and untreated solvent, respectively;

$E_{s}=D_{s} \frac{v}{V} ;$

$v=$ volume of scrubbing phase;

$v=$ volurae of solvent phase;

$\mathrm{n}=$ number of scrubbing volumes, $\mathrm{v}$, that are recycled.

For a practical purification process for the present application, it is necessary to achieve a value of $n$ in the range of 50 to 100 before the DF 1 s reduced to a value that is below abcat 10. Figure 1 shows the calculated effect of $\mathrm{n}$ on the $\mathrm{DF}$ values for $\mathrm{D}_{\mathrm{s}}$ values of 100,500 , and 1000 using an

organic/aqueous phase ratio of unity in a single-stage apparatus. The concentration of the aqueous phase, $C_{a}$, builds up as $n$ increases according to Eq. 3:

$$
\frac{C_{a}}{C_{u s}}=D_{5}\left[1-\left(\frac{E_{s}}{E_{s}+1}\right)^{n}\right]
$$

The transfer of acid impurities from the 30\% TBP phase into the aqueous phase occurs by neutralization and by displacement reactions according to the following equations: 


\section{Neutralization}

$$
\begin{aligned}
& \mathrm{HNO}_{3}+\mathrm{N}_{2} \mathrm{H}_{4} \neq \mathrm{N}_{2} \mathrm{H}_{5} \mathrm{NO}_{3} ; \mathrm{pH}>7 \\
& \mathrm{HDBP}+\mathrm{N}_{2} \mathrm{H}_{4}+\mathrm{N}_{2} \mathrm{H}_{5} \mathrm{DBP} ; \mathrm{pH}>7
\end{aligned}
$$

\section{Displacement}

$$
\begin{aligned}
& \mathrm{HNO}_{3}+\left(\mathrm{N}_{2} \mathrm{H}_{5}\right)_{2} \mathrm{C}_{2} \mathrm{O}_{4}+\mathrm{N}_{2} \mathrm{H}_{5} \mathrm{NO}_{3}+\mathrm{N}_{2} \mathrm{H}_{5}\left(\mathrm{HC}_{2} \mathrm{O}_{4}\right) ; \mathrm{pH}=4 \text { to } 7 \\
& \mathrm{HNO}_{3}+\mathrm{N}_{2} \mathrm{H}_{5}\left(\mathrm{HC}_{2} \mathrm{O}_{4}\right)+\mathrm{N}_{2} \mathrm{H}_{5} \mathrm{NO}_{3}+\mathrm{H}_{2} \mathrm{C}_{2} \mathrm{O}_{4} ; \mathrm{pH}=1 \text { to } 4 \\
& \mathrm{HDBP}+\left(\mathrm{N}_{2} \mathrm{H}_{5}\right)_{2} \mathrm{C}_{2} \mathrm{O}_{4} \ddagger \mathrm{N}_{2} \mathrm{H}_{5} \mathrm{DBP}+\mathrm{N}_{2} \mathrm{H}_{5}\left(\mathrm{HC}_{2} \mathrm{O}_{4}\right) ; \mathrm{pH}=4 \text { to } 7 \\
& \mathrm{HDBP}+\mathrm{N}_{2} \mathrm{H}_{5}\left(\mathrm{HC}_{2} \mathrm{O}_{4}\right) \ddagger \mathrm{N}_{2} \mathrm{H}_{5} \mathrm{DBP}+\mathrm{H}_{2} \mathrm{C}_{2} \mathrm{O}_{4} ; \mathrm{pH}=1 \text { to } 4
\end{aligned}
$$

Neutralization reactions would be expected to be more effective in the transfer of $\mathrm{HDBP}$ than are the displacement reactions of $\mathrm{HDBP}$ because $\mathrm{H}_{2} \mathrm{C}_{2} \mathrm{O}_{4}$ and $\mathrm{HDBP}$ are of comparable acid strength and significant quantities of HDBP are aiways present in the equilibrium depicted in Eqs. (7a) and (7b). Thus, the pH value of the aqueous phase will have an effect on the distribution of HDBP between the phases. The distribution of nitrate ion is much less sensitive to pll values because it is a much stronger acid than oxalic acid.

The complexation reactions with bound metal cation impurities are also best effected under neutral or basic conditions where all of the oxalic acid and alkylphosphoric acids are neutralized. The net reaction shown in Eq. (8) for 
the transfer of $\mathrm{UO}_{2}(\mathrm{DBP})_{2}$ is typical of the transfer mechanism of metal-bound cations and their associated DBP anions from the organic phase into the neutralized aqueous phase:

$$
\begin{gathered}
\mathrm{UO}_{2}(\mathrm{DBP})_{2}+3\left(\mathrm{~N}_{2} \mathrm{H}_{5}\right)_{2} \mathrm{C}_{2} \mathrm{O}_{4}+\left(\mathrm{N}_{2} \mathrm{H}_{5}\right)_{4} \mathrm{UO}_{2}\left(\mathrm{C}_{2} \mathrm{O}_{4}\right)_{3}+2 \mathrm{~N}_{2} \mathrm{H}_{5} \mathrm{DBP} . \\
\text { DESCRIPTION OF APPARATUS }
\end{gathered}
$$

A key feature of the single--stage apparatus is the cylindrical glass, waterjacketed, mixing and settling vessels (Figs. 2-4). The glass permits visual observations of (1) the mixing and settling characteristics of the phases and (2) any precipitate or emulsion accumulation at interfaces. Also, glass is inert to chemical attack in most systems. The separate mixing and settling vessels were constructed from Pyrex glass tubing. Vortex formation is eliminated in the mixer by the use of four, equally spaced baffles wilch extend radially from the vessel wall. Control of temperature is provided by circulation of water through the water jackets via a thermostated water bath. Fluid transfer between the inixer and settler is provided by gravity flow as shown in F1g. 5. The volumes of the mixing and settling vessels are 165 and 280 $\mathrm{mL}$, respectively.

The Impeller and impellex shaft for the mixer were constructed from 304 stainless steel to provide strength. The stirrer shaft fitted with two impellers, four blades each at a pitch of $45^{\circ}$ (Fig. 6) and are located on the shaft at distances such that they are one-third and two-thirds of the distance from the bottom of the mixer to the air-liquid interface. The impeller diameters are 0.4 of the diameter of the mixing vessel. The impellers were driven by 
a Manomatic ${ }^{1}$ motor generator whose speed of rotation controlled by a Cole-Parmer Servod:r: = unft: All interequipment connections shown in Fig. 4 were made using glass tubing and Teflon fittings.

A sampling port (Fig. 5) is provided for taking samples of the phese mixtures while they are in transit from the mixer to the settler. This sampling technj que is of great benefit in determining the phase ratios and compositions. An in-line $\mathrm{pH}$ probe was also installed through a similar port (Fig. 5) to monitor the $\mathrm{pH}$ of the aqueous phase that is discharged from the mixer.

The pumps utilized for phase transport were of the smali laboratory type and were manufactured by Fluid Metering Incorporated (FMI). The FMI pumps were chosen because the interchangeable, puraping heads were avallable to provide the desired range of flow rates and were constructed of a noncorrosive ceramic material. Use of $0.63-\mathrm{cm}\left(1 / 4-\mathrm{in}_{0}\right)$ and $0.95-\mathrm{cm}(3 / 8-\mathrm{in}$,$) heads provided flow$ rate ranges of $0-20$ and $0-46 \mathrm{~mL}^{\circ} \mathrm{min}^{-1}$, respectively. These flow rate ranges were needed to obtain mixer residence times of 2 to $20 \mathrm{~min}$ in the $165-\mathrm{mL}$ mixer.

OPERATIONAL AND EXPERIMENTAL PROCEDURES

The effects of residence time, temperature, and power input to the stirrers were determined using once-through flow of the $30 \%$ TBP phase and tine aqueous hydrazine oxalate scrubber phase, whereas determinations of the effects of the $\mathrm{pH}$ value and Impurity loading of scrubber solutions were made using total recycle of the aqueous phase. Stirrer speeds of $2000 \mathrm{rpm}$, which were measurcd using a stroboscope, were adequate for achieving equilibrium transfer for the

1Servodyne Controller, Cat. No. 4440-30, Cole Palmer Instrument Co., Chicago, IL. 
flow-rate ranges used in this study. Equilibrium transfer was independent of residence time over the range of 2 to $20 \mathrm{~min}$. The $\mathrm{pH}$ of the aqueous phase was monitored continuously, whereas liquid phase samples for the other chemical ana1ysis were withdrawn manually. All analyses of the liquid samples were carried out by the GRNL Analytical Chemistry Division. Nitrate and DBP concentrations of the organic and aqueous phases wers determined using an ion exchange chromatograph. The metal cations, $\mathrm{J0}_{2}{ }^{2+}$ and $\mathrm{Zr}^{4+}$, were determined by $\mathrm{x}$-ray fluoresence. Limits of detection by the analytical methods were as follows:

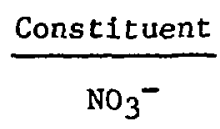

DBP-

$\mathrm{UO}_{2}{ }^{2+}$ $\mathrm{Zr}^{4+}$
Detection limit, $\underline{M}$

$\sim 3 \times 10^{-5}$

$\sim 5 \times 10^{-5}$

$\sim 2 \times 10^{-5}$

$\sim 1 \times 10^{-4}$

These detection 11mits were sufficient for determining that concentrations of these constituents could be maintained at $10^{-4} \underline{M}$ or less in regenerated solvent. However, to utilize the above detection limits, it was necessary to use solvent feeds containing each of the impurity components $\left(\mathrm{DBP}^{-}, \mathrm{Zr}^{4+}, \mathrm{UO}_{2}{ }^{2+}\right.$ and $\left.\mathrm{NO}_{3}^{-}\right)$of a concentration of approximately $10^{-3} \underline{M}$ so that the required $D F$ values of at least 10 could be determined.

RESULTS

The removal of impurities was found to be strongly dependent on the $\mathrm{pH}$ of the aqueous hydrazine oxalate phase. It demonstrated that one volume of hydrazine oxalate was sufficient for treating 100 volumes of simulated spent 
solvent wile giving treated solvent that is acceptable for recycle. The

loading capacity of the aqueous phase was governed by zirconium. At about 0.015 $\underline{M} \mathrm{Zr}^{4+}$ concentration in the aqueous phase, troublesome precipitates were formed.

\section{Effect of Aqueous-Phase pH}

Initial experiments (Fig. 7) showed that the DF value obtained for DBP was strongly dependent on the $\mathrm{pH}$ of the aqueous phase for $\mathrm{pH}$ values of less than about seven. Nitrate removal was essentially independent of $\mathrm{pH}$ above $\mathrm{pH}$ values

- of about four as expected. During all subsequent runs, the $\mathrm{pH}$ was periodically readjusted to the initial 7.5 value when it had dropped to 7.0 . The adjustment is necessary because free hydrazine is consumed by neutralization reactions.

Temperature

Good phase separations were obtained by operating the mixer-settler at $50^{\circ} \mathrm{C}$. Phase separation at $25^{\circ} \mathrm{C}$ was not very satisfactory.

Removal of Impurities

Results of a typical run with a single stage mixer-settler are shown in Table 1. Even after the 240-ml aqueous inventory had been used to treat $9.6 \mathrm{~L}$ of simulated solvent $\left(V_{\mathrm{TS}} / \mathrm{V}_{\mathrm{A}}=4 \mathrm{~J}\right)$, the concentrations of all impurities were at or below the limits of detection. This run was terminated after a $V_{\mathrm{TS}} / \mathrm{V}_{\mathrm{A}}$ value of 40 had been reached because a precipitate of the zirconium dibutylphosphate compound was observed at the interface. Thus it appears that the aqueous-phase loading is limited to about $15 \mathrm{mM} \mathrm{Zr}$. Operability of the equipment was excellent prior to the formation of the interfacial precipitate.

Since actual process solvent contains only about 0.1 mil concentrations of each of the impurities, the results indicate that at least 100 volumes of pro- 
cess solvent can be purified using only one volume of hydrazine oxalate scrubber solution at $\mathrm{pH}=7.5$ while achieving the necessary $\mathrm{DF}$ of about 10 . It is believed, of course, that the DF values are much greater than 10 , but the detection limits of the analytical methods used in this study were not sufficient to determine the actual DF values. 
Table 1. Impurity concentration $\left(C_{\mathrm{TS}}\right)$ in and DF of the treated $30 \%$ TBP as a function of the volume of solvent treated per volume of aqueous solution $\left(\mathrm{V}_{\mathrm{TS}} / \mathrm{V}_{\mathrm{A}}\right)$ at $55^{\circ} \mathrm{C}$

Flow Rates: $8.5 \mathrm{~mL} / \mathrm{min}$ each of simulated spent solvent and $0.7 \mathrm{M} \mathrm{N}_{2} \mathrm{H}_{4}-0.3 \mathrm{M}$ $\mathrm{H}_{2} \mathrm{C}_{2} \mathrm{O}_{4}$ scrubber solution at $\mathrm{pH}=7.5$

Input $30 \% \mathrm{TBP}$ impurity concentrations, $\mathrm{MM}: \mathrm{DBP}^{-}=0.7, \mathrm{U}=0.8, \mathrm{Zr}=1.0$, and $\mathrm{NO}_{3}^{-}=2.4$

Inventory of scrubber solution recycled: $240 \mathrm{~mL}$

\begin{tabular}{lccccc}
\hline $\mathrm{V}_{\mathrm{TS}} / \mathrm{v}_{\mathrm{A}}$ & 4.5 & 10 & 15 & 27 & 40 \\
$\mathrm{DEP}$ & & & & & \\
$\mathrm{C}_{\mathrm{TS}}, \mathrm{mM}$ & $<0.05$ & $<0.05$ & $<0.05$ & $<0.05$ & $<0.05$ \\
$\mathrm{DF}$ & $>14$ & $>14$ & $>14$ & $>14$ & $>14$ \\
$\mathrm{C}_{\mathrm{A}}, \mathrm{mM}$ & 2.6 & 7.8 & 12 & 21 & 27
\end{tabular}

Uranium

$\begin{array}{lccccc}\mathrm{C}_{\mathrm{TS}}, \mathrm{mM} & <0.02 & <0.02 & <0.02 & <0.02 & <0.02 \\ \mathrm{DF} & >36 & >36 & >36 & >36 & >36 \\ \mathrm{C}_{\mathrm{A}}, \mathrm{mM} & 3.4 & 7.3 & 11 & 18 & 27\end{array}$

Zirconium

$\begin{array}{llcccc}\mathrm{C}_{\mathrm{TS}}, \mathrm{mM} & <0.1 & <0.1 & <0.1 & <0.1 & <0.1 \\ \mathrm{DF} & >8 & >8 & >8 & >8 & >8 \\ \mathrm{C}_{\mathrm{A}}, \stackrel{\mathrm{mM}}{2} & 2.9 & 5.7 & 8.1 & 1.2 & 1.6\end{array}$

Nitrate

\begin{tabular}{lccccc}
$\mathrm{C}_{\mathrm{TS}}, \stackrel{\mathrm{mM}}{-}$ & $<0.03$ & $<0.03$ & $<0.03$ & $<0.03$ & $<0.03$ \\
$\mathrm{DF}$ & $>75$ & $>75$ & $>75$ & $>75$ & $>75$ \\
$\mathrm{C}_{\mathrm{A}}, \stackrel{\mathrm{mM}}{-}$ & $1 ! \cdot$ & 24 & 36 & 65 & 96 \\
\hline
\end{tabular}


Lint of Figures

Fig. 1. Calculated theoretical dependency of decontamination factor (DF) on the number of recycles of the scrubbing agent using an organic-tomaqueous phase ratio of unity at several $D_{s}$ values.

Fig. 2. Closeup view of empty mixing vessel.

Fig. 3. Closeup view of settling vessel.

Fig. 4. Photograph of the continuous, single-stage, nixer-settler

apparatus.

Fig. 5. Closeup view of mixing and settling vessels during operation. Mixed phase samples are withdrawn via the stopcock located between the vessels.

Fig. 6. Impeller used for phase mixing.

Fig. 7. Change in the DF value for DBP and the pH of the aqueous phase as the volume of organic solvent treated by the fixed inventory of aqueous scrub liquid is increased. 
Fi: 1

ORNL DWG 81-852

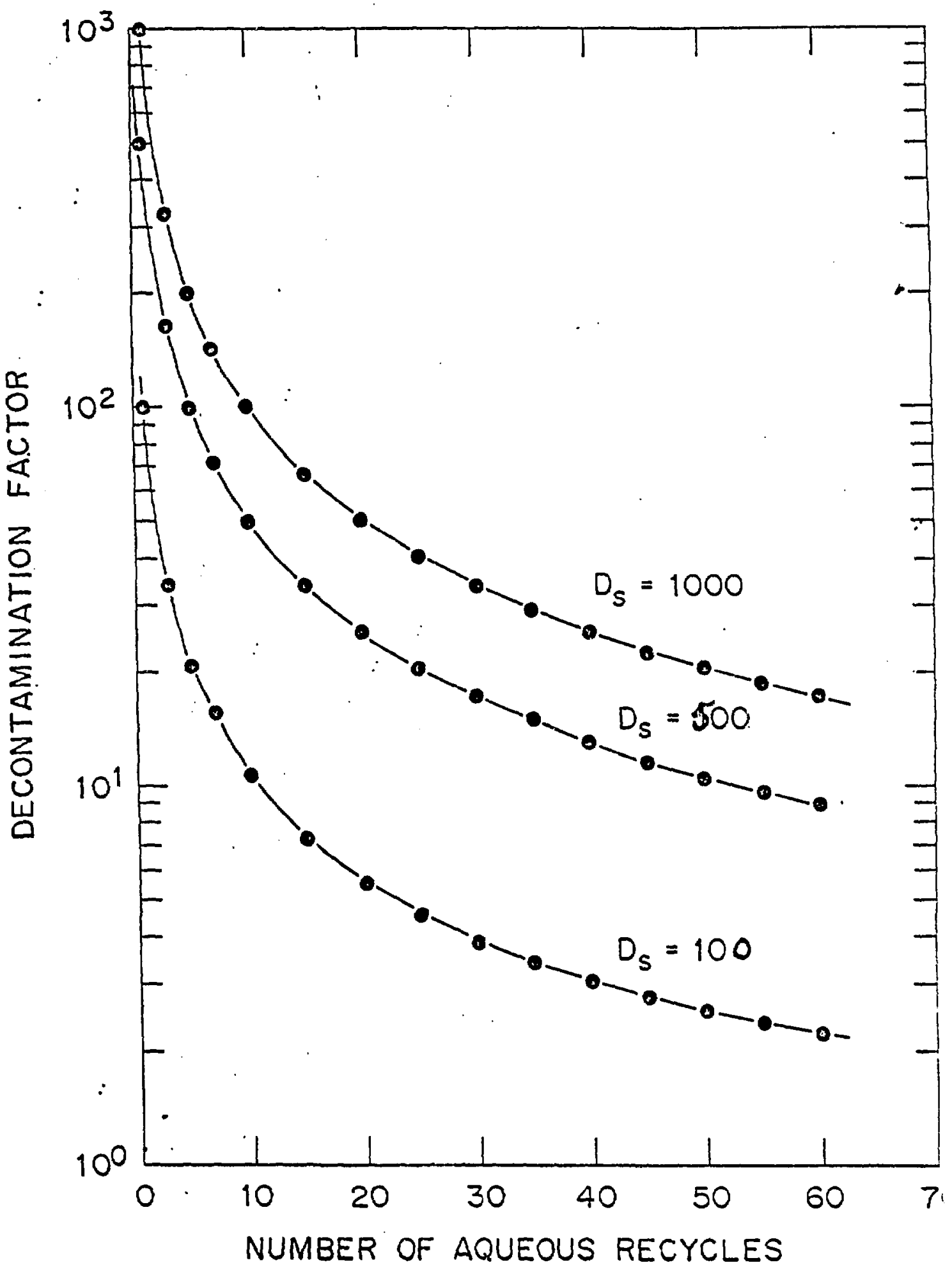




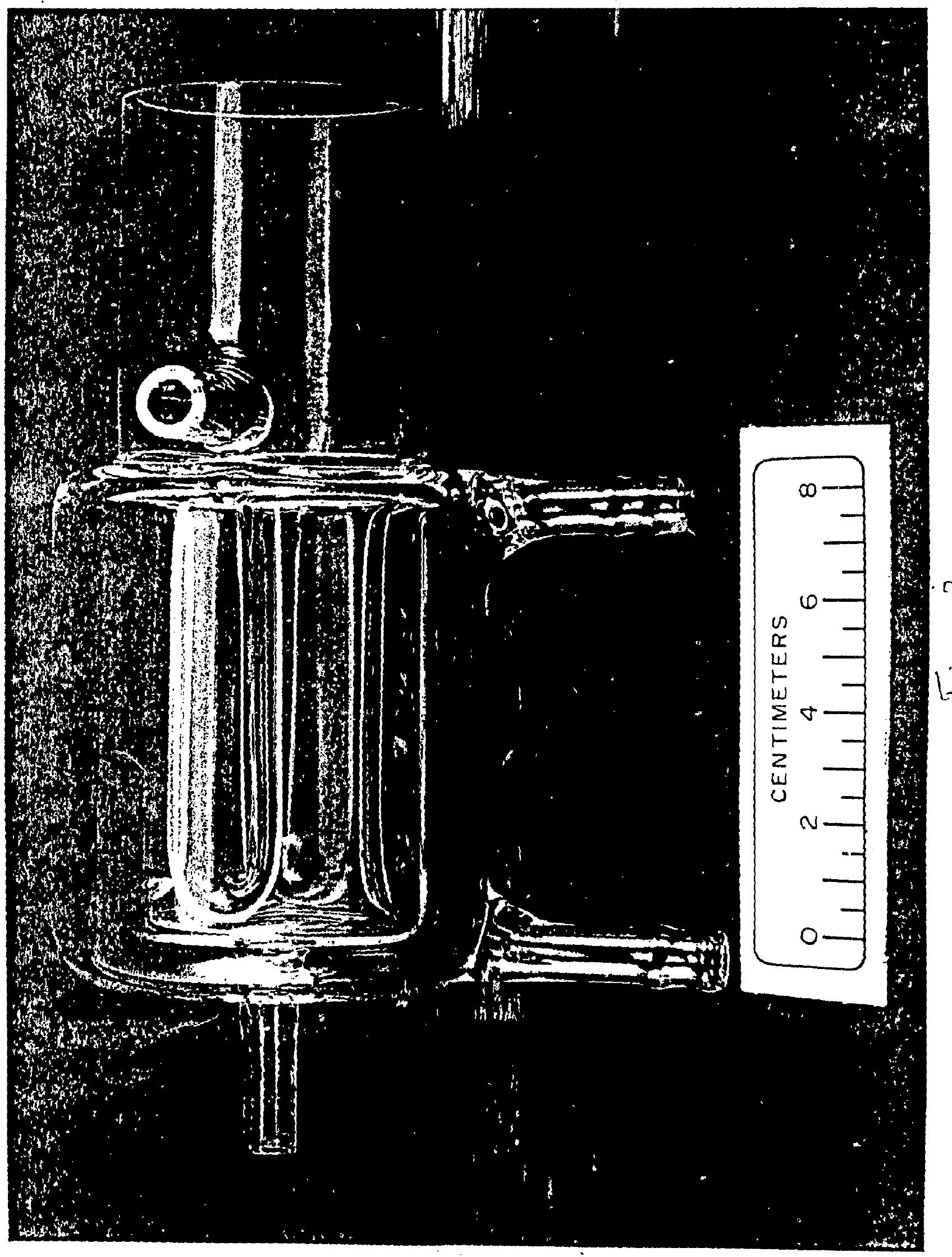




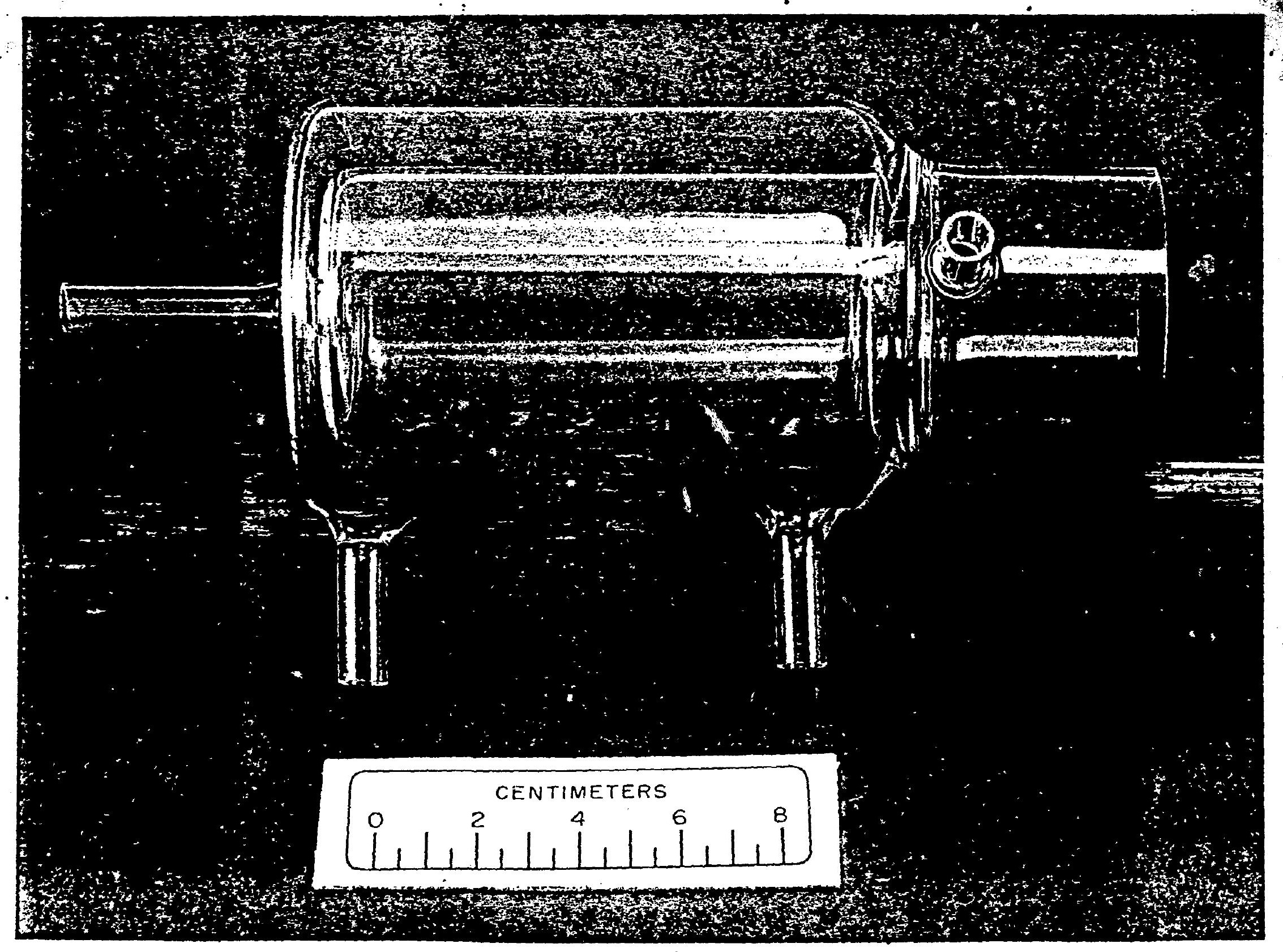




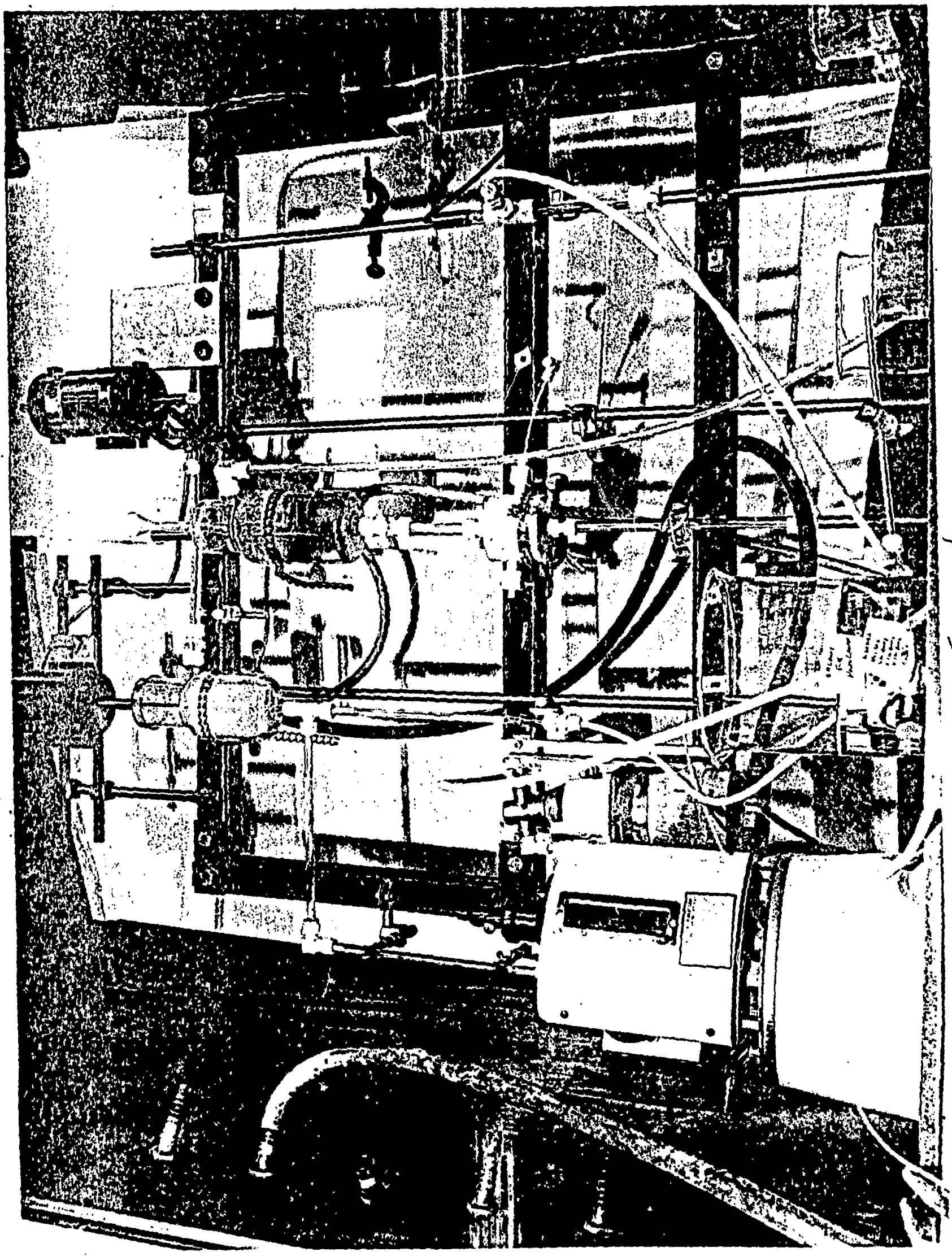




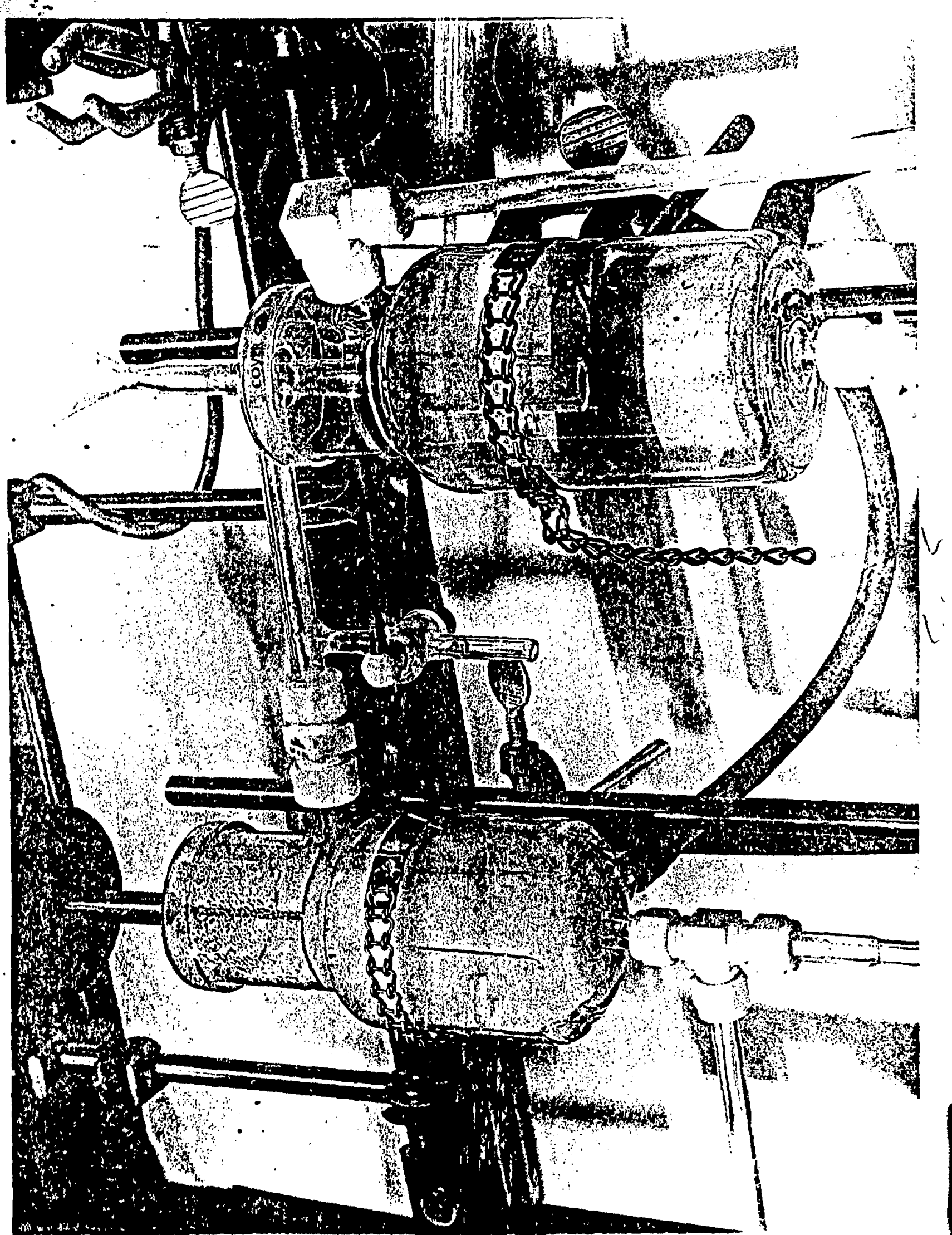





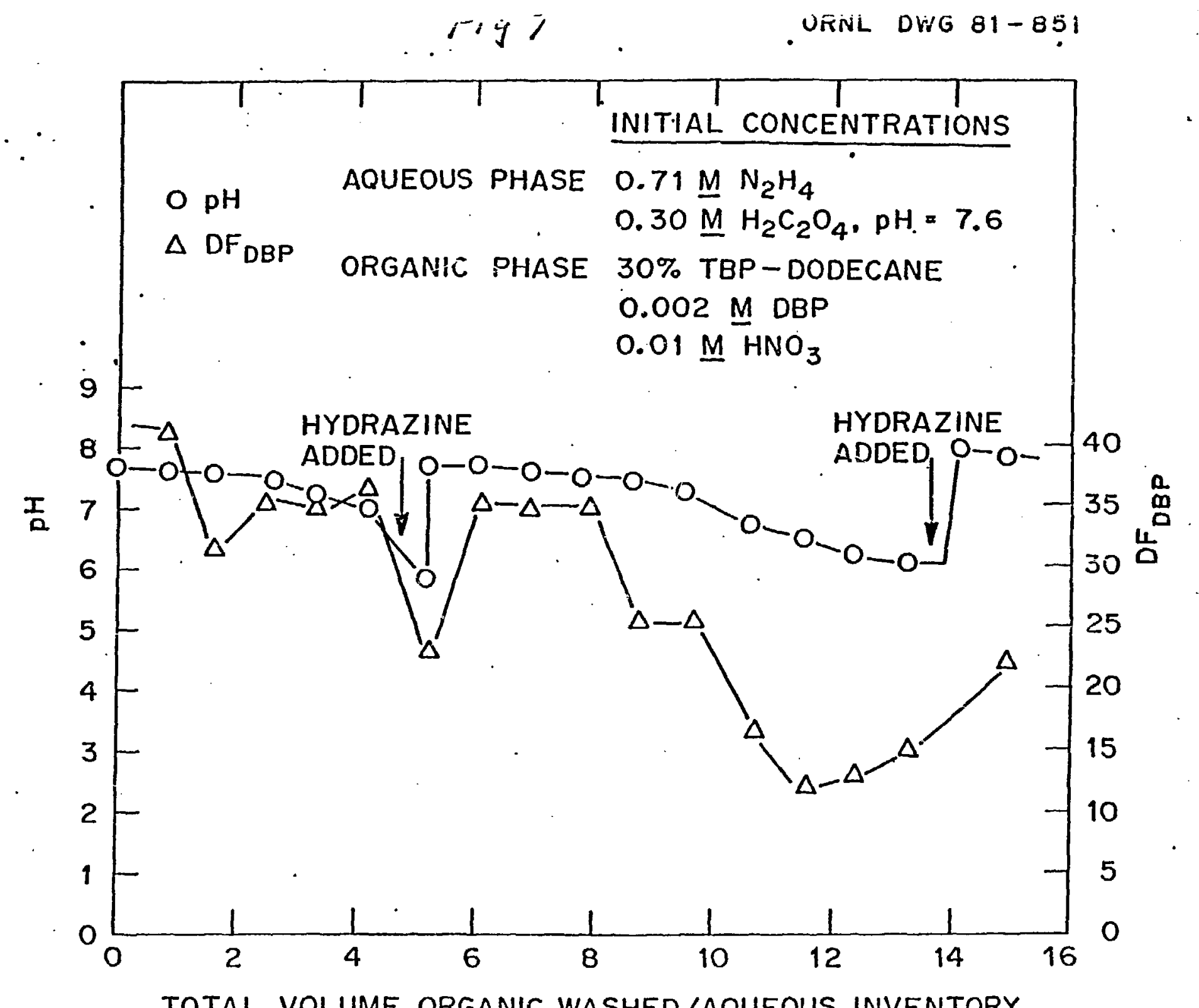

TOTAL VOLUME ORGANIC WASHED/AQUEOUS INVENTORY 